\title{
IMPROVING OF MATERIAL FLOW IN AUTOMOBILE ENTERPRISE
}

\author{
Veronika Verebová \\ Technical university of Košice, Institute of Logistics, Park Komenského 14, 04384 Košice, Slovakia \\ veronika.verebova@gmail.com
}

\begin{abstract}
Keywords: material flow, logistics, information systems, simulation systems, system analysis
Abstract: Today's market puts more and more pressure on manufacturing companies. If the company wants to keep on market and to prosper, it is necessary to constantly innovation of the products, to better calculate the prices, to control costs, to be flexible in the relationship to the customer. Requirements on the logistics are constantly getting harder and more differentiated. Production companies are forced to tolerate piece production for the customer with rapid supplies. So that the production could be effectively implemented, it is necessary to constantly maintain inputs and outputs of material with customer requirements. The aim of logistics is to increase the efficiency of logistical processes, since only properly working logistical processes ensure the cost competitive and properly functioning society. Each of companies understands the logistics from different views. It depends on the specific company, field of activity and sector. For one of the companies it is a planning for another it is purchase and shipping, or handling with materials in the production.
\end{abstract}

\section{Introduction}

To ensure the fluent material flow it is necessary to constantly monitor and provide input and output of material according to customers' requirements. For material flow there are a number of definitions, however, I define at least one: "Material flow is controlled by the movement of material, raw material, semi-finished products, products in progress, the media and others in the production and distribution sphere" [1].

To streamline the material flow in translation means to find the effective level, to ensure a smooth flow of material, to prevent from downtimes or missing material, to minimize the costs, staff, to reduce the time of transport operations [1].

Material flow analysis mainly takes place in order to effectively manipulate with the material through the various steps of the production process. In order to make the flow effective, it is necessary to ensure direct flow of material by the shortest way and without unnecessary stops, obstacles, detours and counter movement. „In practice, we know several methods of material flow analysis, which can be divided into 4 groups. Wherein each of the groups has different conditions of relations of basic input SPMT data, compound of material and its quantity.

- Phase "A" - characterizes such a production system that produces a few types of product in a large number. In this case, the material flow is analysed by the production process method scheme.

- Phase "B" - characterizes the company with relatively large production volume and the relatively wider range of products of production program. For the analysis of material flow in this case, we use a scheme of production process for more products.

- Phase " $\mathrm{C}$ "- is a transient phase that characterizes the production of production process, in which the middle number figures, but a wide range of similar products. After the grouping of similar products, similar technological processes and selection of product representatives, there is applied, according to the number of representatives, either method of phase "A" or "B".

- Phase "D"- characterizes the company with the production of small volume but relatively very different product range. For analysis in this case is preferably used checkerboard table [1].

It is possible to divide material flow into two main groups:

- active group of material flow, where there are transport-handling and storage devices classified,

- passive group of material flow, where there are material, raw materials semi-finished products classified [2].

The role of the active logistical elements is to physically secure movement and manipulation of passive elements. On the other hand, passive elements are during handling and transport more like the handling unit with which it is manipulated.

French multinational company with production sites across Slovakia manufactures components for the automobile industry. Košice plant has been producing door panels, which assembly is realized in a Boblingen. The material is provided to the company by 70 suppliers, who are mainly from abroad. The main supplier for leather and PVC is Hungary, for the input material is the supplier from Hungary and Spain.

\section{Material flow, warehouse - production}

After the material entering to the warehouse and subsequent delivery to the chipping, the process is managed through Kanban. The material is, after the chipping of required components, gradually moved to the 


\section{IMPROVING OF MATERIAL FLOW IN AUTOMOBILE ENTERPRISE}

Veronika Verebová

Rollercoating, by using the FIFO system, from where it is further moved by FIFO to lamination. Material is after the lamination temporary stored in the shopstock, where there are consoles with the chipped material completed. From the shopstock, again by the Kanban system, the operatorKanban specialist supplies workplaces according to the regular control which material is missing on the given workplace. After the recording of missing material and returning to the shopstock for material, the specialist supplies the given workplace and subsequently returns Kanban card back to chipping, where the released material is chipped again.
After the entering of material into the warehouse, following input check made by the worker, operators supply individual workplaces with the material. These workplaces are supplied by so called electrical logistical trains. Each employee has his own "logistical train " that supplies the assigned workplaces by regular supply of input production material from one side of the workplace, while at the same time it takes finished products intended for the warehouse for the temporary storage from the other. Operators also have set times for supply and collection of finished products. At each shift there are four operators, where each serves assigned workplaces.

material flow

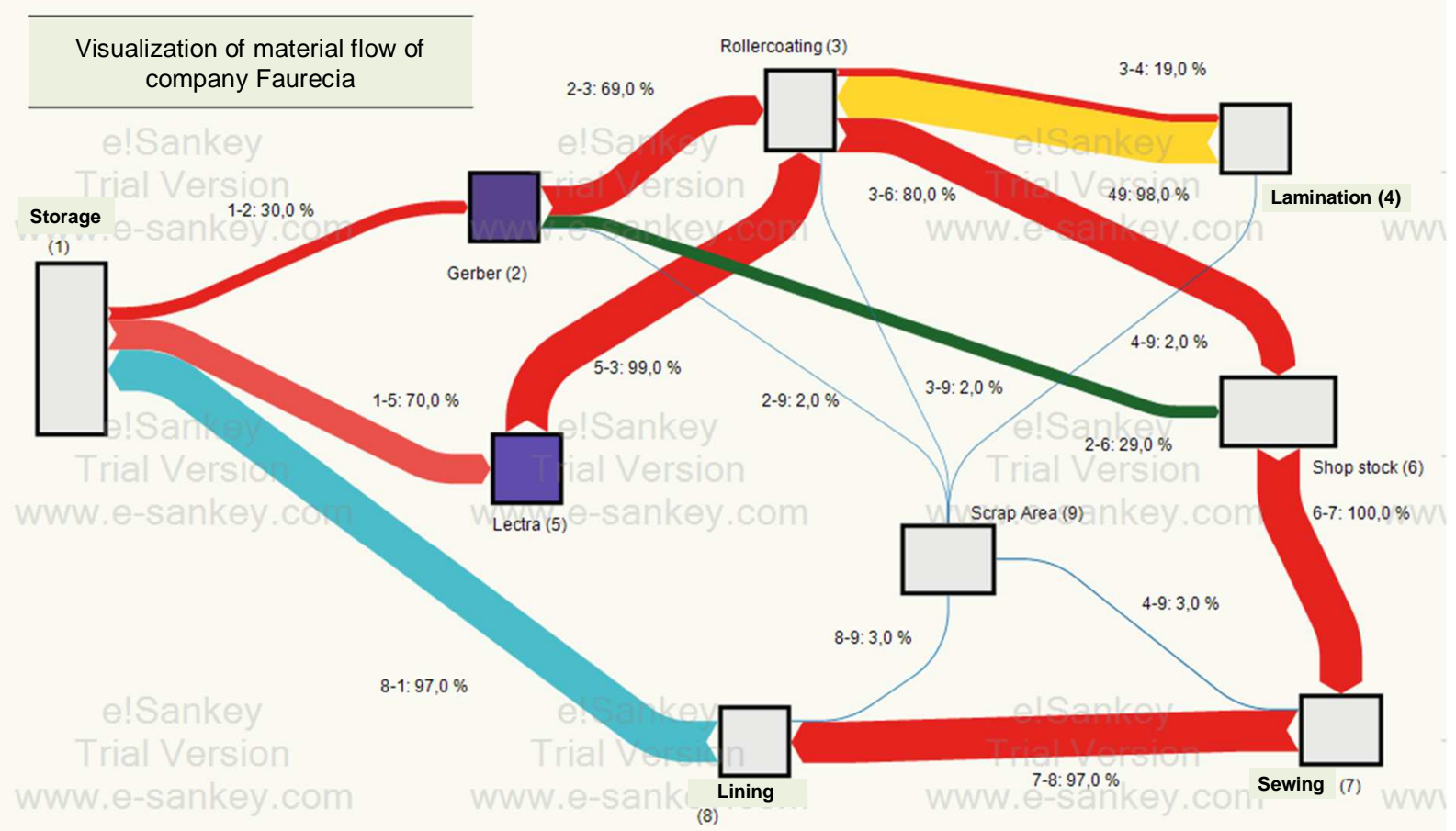

Figure 1 Visualization of material flow

Figure 1 is a visual representation of material flow, which is moved from the warehouse after the input check of the material (leather or PVC) to the chipping, where there is material rolled on the disc, while the leather is prepared after the visual control and defect indication for the chipping of components, on which is the applied glue, foam, if the perforation is necessary, then it is moved to the specialized workplace in Germany. Stabling of single components of the leather or PVC follows after this process. Stabled components are further moved to the workplace where the actual coating on the woodfiber takes place.

For the production of already mentioned door panels a number of components are required, woodfiber is used as the basis on which are subsequently used various plastics, and finally it is the leather or PVC material, under which is located the base foam or even supplementary foam that is used for softening of the material.

\section{Production process}

The process begins with the income of the material into the input warehouse, where it continues according to the type of the material (PVC, leather) farther, where after the chopping of components, the material farther moves to Rollercoating and some components which are intended to lamination, which are parts intended mainly for the production of car, pass the lamination, where the foam is applied to the bottom of the material. Subsequently, the pieces are placed in shopstock (temporary warehouse) where the operator farther supplies the sewing workplace with the material, where the components after the sewing wander farther to the

$$
\sim 6 \sim
$$




\section{IMPROVING OF MATERIAL FLOW IN AUTOMOBILE ENTERPRISE}

Veronika Verebová

final coating line. Leather is supplied from the warehouse of input material where it is subsequently after the visual inspection and identification of defects by the operator with the marker for it, components will be chipped. The leather is covered by the transparent protective film before the chipping to prevent possible damage of the material. We distinguish three areas of cutting, zone A, B, $\mathrm{C}$, while the highest quality requirements are placed on zone $\mathrm{A}$ and in zone $\mathrm{C}$ there are already authorized certain types of defects.
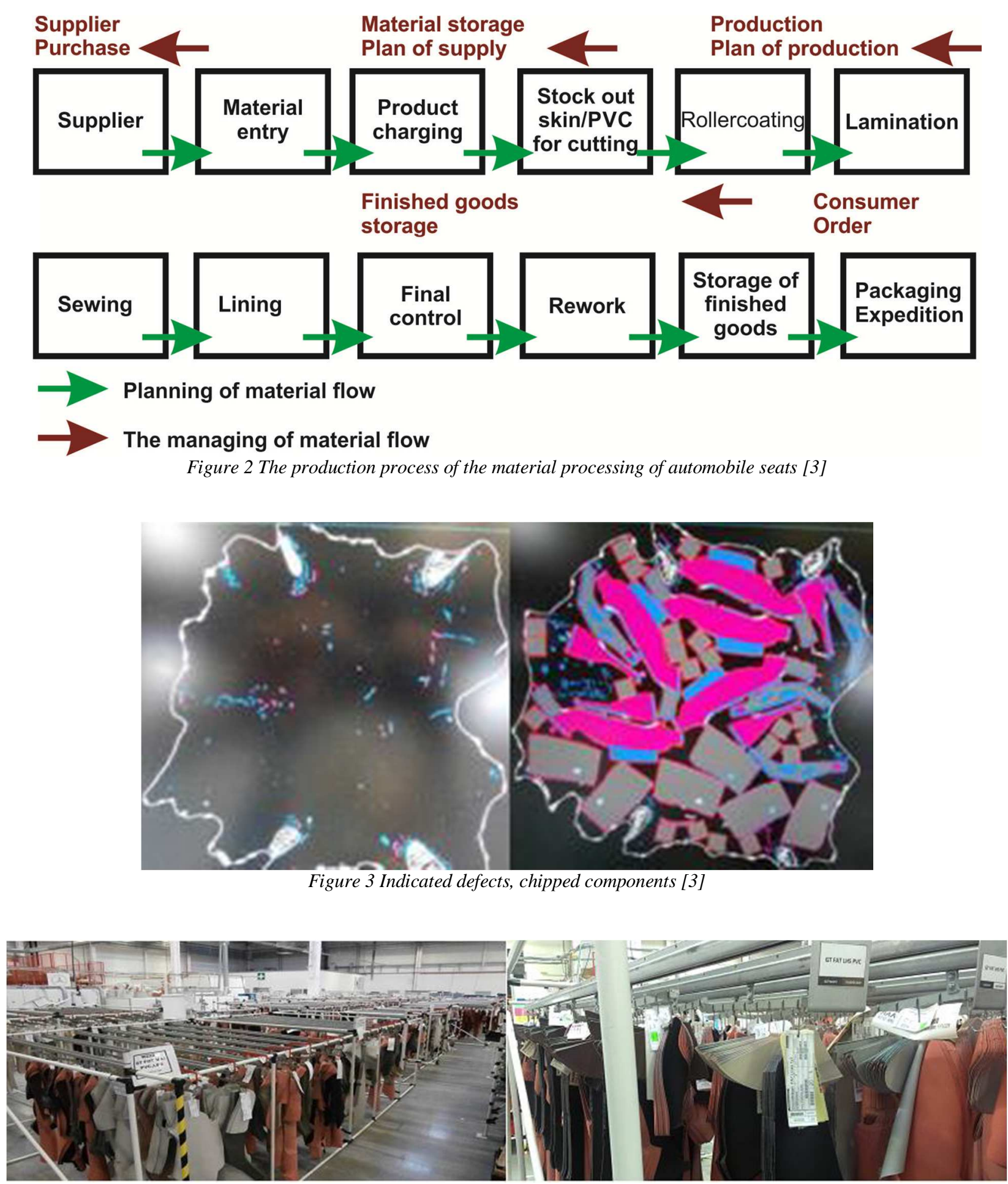

Figure 4 Shopstock (temporary warehouse of the material) [3]

$$
\sim 7 \sim
$$




\section{The streamlining of material flow}

Current problems in production can be improved by proper functioning of the Kanban system. However, the system requires careful implementation, employee training, or change of the layout. The analysis reveals that the company had introduced pull production management system also based on Kanban. However, when conducting a detailed analysis, the problem was detected when using the system, but also there was created space for the implementation of Kanban, and more precisely in the coating process.

When using Kanban system, it is necessary to storage the material into the crates and then on the shelves. This activity would be provided by the operator servicing the logistical train. At the moment, when operator on the coating workplace would have consumed all the material, GAP leader would provide desired material stored in the crate and operator would be continued in the work. Each piece should have its Kanban card that would be included in the sequencer. The operator would read from the given card what he needs to produce. Subsequently, the card would travelled along with the material throughout the production process to the final control, which, after a careful checking of the product along with the Kanban card, can store the product on the shelf ready to save of the finished products before moving of these pieces into the warehouse. After the withdrawal of pieces from the shelves, the Kanban card is returned back to the sequencer on the sewing workplace.

\section{The streamlining of warehouse arrangement}

The defined storage, just like the system of products laying on the defined space represent the current active state in the storage. For the following years, it would be appropriate to determine the storage space for the most frequently used material that would be as close as possible to the production. This means, that it is firstly necessary to define the most used material and vice versa with the least. Then, it is necessary to define the storage space that would be the closest to the place of the removal place. The gain is represented by the savings in the manipulation time of the storage workers, removal and by the prevention of the downtime when the shifts change.

\section{Conclusions}

According to the analysis, the main causes of the downtime and missing material was the long waiting for input material scanning, which had to be transcribed from the storage and also the crossing of the two logistic trains, which endangers the production, because of the lack of continuous income of material. Another observed problem was the disregard for Kanban system by employees. We should divide disregard into the employees, who refused to respect it and employees, who did not have sufficient information about the given system. One of the benefits for the company is the introduction of the system Warehousemanagement system, which ensures perfect overview of the material and finished products in the company, specify the warehouse operations and significantly reduce error rates. At system boot and its perfect overview of the material and products in warehouse, there would be a clarifying of order picking and clarification. By this it would no longer be necessary that operators would be searched at the last minute in the warehouse products intended for shipment. Another important factor is that the WMS system is not based on the human factor and therefor there is no threat of errors that are often caused by the human factor. In this case, it would save the time that the company had spent on employee training, as in the WMS system there is no need for lengthy training, system itself navigates employee where he can the given product finds. Subsequently, the system will announce using a voice tag also the right number needed for shipping. The only training that had to be undergo by the employees is the one, that teaches how to as effectively as possible save the material/product on the pallet, how to fix, stack and sort it.

\section{References}

[1] BIGOŠ, P. et al.: Materiálové toky a logistika, Košice, p. 156, 2008. (Original in Slovak)

[2] ŠADEROVÁ, J.: Tok tovaru logistickým retazcom vel'koobchodu, [Online], Available: http://web.tuke.sk/transportlogistics/issues/normal/201 0/N18/03_saderova.pdf [07 Jan 2015], 2015.

[3] VEREBOVÁ, V.: Návrh pre zefektívnenie materiálového toku $v$ smere sklad-výroba vo firme Faurecia Slovakia, s.r.o., p. 54, 2015. (Original in Slovak)

\section{Review process}

Single-blind peer reviewed process by two reviewers. 